\section{Prescriptions, licences and evidence}

Sir: Healy \& Nutt state (Psychiatric Bulletin November, 22, 680-684) that "the defence unions would not support the prescriber prescribing off-licence in the event that things went wrong". On behalf of both the Medical Protection Society and the Medical Defence Union, I write to correct this misleading statement.

Members of our respective organisations are entitled to apply for advice and assistance in relation to any legal problem arising from their medical practice. So long as the prescription of a drug 'off-licence' is a part of normal clinical practice, we would of course respond to a member's request for assistance.

As a separate issue, if litigation were to ensue following an adverse event then, as in all medical negligence cases, the defensibility of the doctors' management is dependent upon obtaining expert support from other doctors practising in that (sub-)speciality. Broadly speaking, provided there is supportive expert opinion, then the claim will be defensible, irrespective of the wording of the drug licence.

We trust this clarifies the position for the readership of your journal.

GERARD PANTING, Head of Policy and External Relations, Medical Protection Society, 33 Cavendish Square, London W1M OPS

\section{Prescribing antipsychotics in child psychiatry}

Sir: Slaveska et al (Psychiatric Bulletin, November 1998, 22, 685-687) have highlighted an important problem for child psychiatrists. Over two years only $64 \%$ of respondents had had contact with a child with psychosis. The number of cases seen was between one and 12 (median one case per consultant). One has to ask if these child psychiatrists can retain competence as prescribers of antipsychotics. Although the prevalence of psychosis is low in child psychiatry, the next child referred may be psychotic and in urgent need of medication. Child psychiatrists cannot therefore absolve themselves from responsibility for keeping up-to-date with new antipsychotics and prescribing them when appropriate. Another complication arises with the prescribing of clozapine in paediatric populations. In the study by Kumra et al (1996), toxic effects including neutropenia and seizures were more common than in adult populations. One approach to keeping child psychiatrists up-todate with drug treatment might be to set up groups where the ongoing management of psychotic child referrals was discussed.

\section{Reference}

Kumra S., Frazier, J. A., Jacobsen, L. K., et al (1996) Childhood-onset schizophrenia. A double-blind clozapine-haloperidol comparison. Archives of General Psychiatry, 63, 1090-1097.

HOWARD ROBERTS, Consultant in Child and Adolescent Psychiatry, 73 Onslow Gardens, London N1O $3 J Y$

\section{Use of antipsychotics by child and adolescent psychiatrists}

Sir: Having recently completed a survey of 46 child and adolescent psychiatrists in the Wessex region (37 consultants and nine senior registrars) on the use of antipsychotics in first-episode psychoses, we found Slaveska et al's (1998) paper particularly apposite. Our findings, however, contrast sharply. We developed a questionnaire, asking about the drugs psychiatrists would use to treat first episodes of psychotic illnesses. Forty-one out of $46(89 \%)$ questionnaires were returned. Four respondents reported they never prescribed antipsychotics and did not complete the questionnaire, while one returned a blank questionnaire. The respondents had a mean of 9.8 years of experience in child and adolescent psychiatry. Fifty per cent would use risperidone, olanzapine or "a new antipsychotic" as their first choice, $24 \%$ would not prescribe new atypical antipsychotic as their first or second choice, while $12 \%$ would only use conventional antipsychotics as defined by Thomas \& Lewis (1998). The doses used ranged between 200 and $800 \mathrm{mg}$ chlorpromazine equivalents. Clinicians reported that differing side-effect profile, observing trends in psychiatric practice, training with clinicians with an established prescribing practice and adverse personal experience guided them most in their prescribing. Therefore, we found that the majority of the Wessex child and adolescent psychiatrists would prescribe atypical antipsychotics, as first choice, a finding that is very different from that found by Slaveska et al (1998). The wide variations in findings, however, highlights the need for further discussions on good medical treatment in this particular age group. especially as their first experience with psychopharmacological treatment may well significantly influence their future compliance. 